\title{
A revacinação BCG em escolares: um estudo pioneiro
}

\author{
$B C G$ revaccination in school children: a pioneer study
}

\author{
Clemax do Couto Santana*
}

$\mathbf{O}$ stir uma data comemorativa para a vacina demonstra a sua importância na história da humanidade. Essa vacina encerra inúmeras controvérsias desde que foi empregada pela primeira vez em humanos, em 1921, em uma maternidade de Paris, por iniciativa de Calmette, assim coroando a laboriosa experiência iniciada em 1901 por Nocard e Guérin. Esse produto imunibiológico fôra obtido pela atenuação do Mycobacterium bovis após treze anos de pesquisas, sofreu inúmeras resistências a seu uso na população, e mais tarde foi denominado bacilo de Calmette e Guérin ${ }^{1}$. Para se ter noção da manifestação popular de então, são conhecidas as charges da imprensa em que se vê pessoas vacinadas com BCG passando a ter feições de bovinos, ridicularizando a vacina e amedrontando a população.

A vacinação BCG chegou ao Brasil em 1927, após ter sido introduzida para aplicação em massa na França e em outros países. Tal se deu graças ao empenho do professor Arlindo de Assis. Foi preparada com uma cepa proveniente do BCG original que mais tarde, cultivada pela Fundação Ataulpho de Paiva, adquiriu características próprias, constituindo-se na cepa BCG Moreau - Rio de Janeiro, que revelou possuir a menor virulência residual em experimentos animais, e menor gravidade da lesão cutânea em crianças, produzindo resposta tuberculínica mais intensa e duradoura ${ }^{1}$. Até 1973 foi usada por via oral, e, desde então, pela via intradérmica.

Estima-se que entre 1948 a 1974 tenham sido aplicadas 1,9 bilhões de doses em todo o mundo.

A vacina deve ser administrada ao nascimento, mesmo em recém-nascidos com baixo peso de nascimento (2.000$2.499 \mathrm{~g})$, já que não há comprometimento no desenvolvimento da imunidade celular ${ }^{2}$. Neste particular, já nos primeiros anos da década de 1990 , Ferreira et al. ${ }^{3}$ contribuíram para firmar a segurança do BCG em crianças com mais de $2 \mathrm{~kg}$, mudar as normas anteriormente vigentes de vacinação no Brasil e despertar o interesse do primeiro autor na

\footnotetext{
* Professor Adjunto do Departamento de Pediatria da Faculdade de Medicina da Universidade Federal do Rio de Janeiro (UFRJ). Presidente do Departamento Científico de Pneumologia da SBP.
}

vacinação e agora na revacinação BCG, a julgar pelo artigo desse número do Jornal de Pediatria ${ }^{4}$.

Após a vacinação BCG, em raras situações, pode ocorrer reações como a linfadenite, uma erupção cutânea fugaz e benigna, ou doença disseminada. Esta é rara, de difícil tratamento, e está relacionada a imunodeficiências graves $^{5,6}$.

Foram desenvolvidos vários ensaios clínicos controlados sobre a eficácia da BCG contra a tuberculose entre os anos de 1950 a 1970, que envolveram cerca de 150.000 pessoas, e os resultados variaram de 0 a $80 \%$ de eficácia. Nos últimos 20 anos, outras investigações realizadas principalmente em países em desenvolvimento, evidenciaram a eficácia da vacina, sendo que em relação às formas graves (miliar e meningoencefalite), esta oscilou entre $82,4 \%$ e $99,6 \%$.

Desde então, há consenso na literatura mundial de que o BCG intradérmico é eficaz contra formas graves de tuberculose primária ${ }^{1,5}$.

O BCG é uma das vacinas mais estudadas, e a que menos reações adversas produz ${ }^{7}$. Na América Latina e especialmente no Brasil, devido à cepa Moreau, esses efeitos são extremamente raros 5 .

A revacinação BCG foi introduzida no Brasil em 1994, como reforço à primo-vacinação feita ao nascer. Essa política de vacinação se deveu à constatação, na época, da ocorrência de casos graves de tuberculose, como a meningoencefalite, em jovens, faixa etária que anteriormente era relativamente poupada ${ }^{8}$.

A perda do efeito protetor da primo-vacinação com BCG pôde ser identificada em alguns países com características diferentes entre si, como é o caso da Inglaterra, Noruega e Índia, para citar locais onde houve eficácia elevada da vacina, a qual decaiu com o passar do tempo. Admite-se que nas áreas onde há grande número de desnutridos, o tempo de proteção da vacina seja encurtado. Alguns países, como a Hungria, adotaram a revacinação BCG e constataram redução da incidência de tuberculose na população ${ }^{2,5,6,8}$. Ainda não foi publicado nenhum ensaio controlado sobre revacinação BCG. O primeiro será o 
estudo brasileiro que vem se desenvolvendo em Salvador e Manaus sob a coordenação do Ministério da Saúde, do Instituto de Medicina Social (Bahia) e da London School of Medicine, que incluiu mais de 300.000 crianças e adolescentes, e cujos resultados são aguardados para breve.

Levando em conta a grande evasão escolar existente no país, o Ministério da Saúde optou por recomendar o reforço da vacinação BCG à entrada da escola, e não na adolescência, deixando, porém, a cargo dos Estados a escolha da época de maior abrangência para a revacinação. Assim, esta deverá ser feita por volta dos 6 anos, quando a criança for admitida à escola. A revacinação está indicada também em crianças que receberam a vacina e não desenvolveram cicatriz até 6 meses após. É contra-indicada em crianças infectadas pelo HIV, ou com imunodeficiências congênitas ou adquiridas ${ }^{2}$.

O início da revacinação BCG no Brasil motivou incertezas quanto a possíveis efeitos adversos que poderiam vir a ocorrer, gerando reações locais ou sistêmicas indesejáveis de maior ou menor gravidade. Isso, porque se sabe que o comportamento dos vacinados com BCG nem sempre obedece à cronologia habitual, na qual se identifica a formação da hiperemia, enduração, crosta, úlcera e cicatriz no período de dez semanas. Pelo fato de que os revacinados já haviam recebido uma dose de BCG ao nascer, admitia-se que esse novo estímulo imunológico fosse desencadear grandes reações locais no local de aplicação, decorrentes da reativação da imunidade celular do indivíduo. A preocupação com relação aos possíveis efeitos locais indesejáveis da BCG, sentida em todo país naquele momento, motivou o grupo de pesquisadores liderados por Ferreira a desenvolver o trabalho agora publicado ${ }^{4}$. Nele discute-se a manifestação de hipersensibilidade ao bacilo da vacina induzida pela memória imunológica da vacinação BCG ao nascer ou eventualmente decorrente de infecções naturais pelo $M$. tuberculosis. Há mais de 20 anos, quando se introduziu a BCG por via intradérmica no Brasil, foram vacinados escolares, muitos dos quais já haviam se infectado pelo $M$. tuberculosis e recebido a BCG por via oral. Naquela época o percentual de efeitos locais indesejáveis da vacina fôra de apenas $0,04 \%$.

O Ministério da Saúde publicou, à época do início da revacinação, um manual no qual se definem as complicações da vacina e são apresentadas possibilidades de tratamento desses efeitos adversos ${ }^{2}$. Há poucos relatos de complicações da revacinação BCG na literatura, bem como não há unanimidade de condutas ${ }^{10}$.

Os resultados aqui apresentados por Ferreira et al. ${ }^{4}$, em investigação bem conduzida por equipe experiente em vacinação de campo, contribui de forma expressiva para o melhor conhecimento das reações esperadas na revacinação BCG. Os autores discutem a reação de hipersensibilidade ou Fenômeno de Koch, destacando que "a formação de halo hiperemiado e endurado ao redor da cicatriz vacinal anterior observado em algumas crianças... pode refletir a grande mobilização inflamatória bloqueadora induzida pela vacina para focos externos a seu ponto de inoculação, reforçando um dos possíveis mecanismos patogênicos de proteção induzido pela BCG" e, sem constatar nenhum efeito adverso grave da vacina no seu trabalho, desfazem o temor inicial pela revacinação em escolares, concluindo que esta, "independente do conhecimento da condição tuberculínica prévia, produz intensa, precoce e persistente lesão cutânea, sendo essa reação extensa restrita ao local da aplicação, com menor envolvimento de linfonodos regionais que o observado na primo-vacinação".

\section{Referências bibliográficas}

1 Camargos PAM, Souza GRM. Vacinação BCG. In: Sant'Anna $\mathrm{CC}$, editor. Tuberculose na infância e na adolescência. Rio de Janeiro: Atheneu; 2002.p.205-17.

2. Brasil. Ministério da Saúde. Coordenação Nacional de Pneumologia Sanitária. Segundo informe técnico sobre vacinação/ revacinação BCG. Brasília: Centro de Documentação; 1994.

3. Ferreira AA, Bunn-Moreno MM, Sant Anna CC, Ferreira MM. BCG vaccination in low birth weight newborns: analysis of lymphocyte proliferation, IL-2 generation and intradermal reaction to PPD. Tuber Lung Dis 1996; 77:476-81.

4. Ferreira AA, Ferreira MFC, Macedo EA, Cunha I, Santos SL, Reis AR, et al. Revacinação BCG em escolares: evolução da lesão vacinal entre 48 horas e 10 semanas. J Pediatr (Rio J) 2002;78(4):289-94.

5. Rosemberg J, Tarantino AB. Tuberculose. In: Tarantino AB, editor. Doenças pulmonares. $4^{\mathrm{a}}$ ed. Rio de Janeiro: Guanabara; 1997.p.323-418.

6. Karnak I, Senocak ME, Buyukpamukcu N, Gocmen A. Is BCG vaccine innocent? Pediatr Surg Int 1997; 12:220-3.

7. Lotte A, Wasz-Hockert O, Poisson N, Engbaek H, Landmann H, Quast U, et al. Seconde étude de l' UICTMR sur les complications dues à la vaccination intradermique par le BCG. Bull Union Int Tuberc Mal Resp 1988; 63:50-62.

8. Sant'Anna CC. Ressurgimento da tuberculose e revacinação BCG [editorial]. Arq Bras Pediatr 1995; 2:151.

9. Souza GRM, Sant'Anna CC, Lapa e Silva JR, Mano DB, Bethlem NM. Intradermal BCG vaccination complication - analysis of 51 cases. Tubercle 1983; 64:23-7.

10. Grime P, Ormerod P. BCG-revaccination. Thorax 2001; 741-2. 